\title{
Innovative Practice of Graduation Design Mode in Major of Art and Design
}

\author{
Junzhu Zhang \\ School of Design \\ Shunde Polytechnic \\ Shunde, China
}

\begin{abstract}
Purpose: break through teaching paradigm of graduation design of traditional art and design, solve the current situation that contradiction exists between cultivation of art and design talents and requirements of art and design talents, according to requirements of talent cultivation in specialty of art and design, and deepen teaching idea and connotation that cooperate with teaching and education. Method: Demonstrate through adopting methods such as literature exploration, theoretical research and teaching practice. Conclusions: Express certainty for implementation of teachers' teaching and students' education. It can help teachers to adopt good points and avoid shortcomings, give play to professional strong point and learn from each other to achieve the effect that teaching benefits teachers as well as students; it can effectively improve students' academic record, guide students to take the initiative to ask questions, put forward questions and discuss questions to form good atmosphere of active learning; it can strengthen communication and connection between teachers and students as well as students and students, create team culture, cultivate cooperative spirit of group; increase research and discussion on course teaching and promote teaching reform.
\end{abstract}

Keywords-art and design; cross-border integration; graduation design; cooperative teaching; cooperative education

\section{INTRODUCTION}

\section{A. Designers Need to Have Integration Capability}

The influence of globalization and diversification and the integration of cross-industry field decide that design needs cross-border integration. Designers need to have integration capability and collaborative design capability. Compared with challenges faced by designers in the past, the challenges faced by them today are complicated. They have to face a large number of unknown problems that it is impossible to define the industry. Design is just like a system in the industry. The work of design has become a work of cross-border integration. Except for design expertise, design aesthetics and ergonomics, designers shall also have diversified knowledge in other fields, such as anthropology, sociology, psychology and marketing. Only by learning knowledge in other professional fields to cover the shortage in pure design thinking can designers have design capability of cross-border integration.

[Fund program] Funding project for training plan of excellent young teachers in institutions of higher learning in Guangdong province; project number: Yq2013200.

[CLC] G642 [Document Code] A [Article Number]

\section{B. Designers Need to Have TeamWork Spirit}

At present, it is the era of teamwork. Designers need to have "expression, communication, sharing, respect, and care and team-work spirit". The industry generally reflects that the art and design graduates at present have poor design practical ability, take a long time to adapt to job position and lack innovation, teamwork and humanistic spirit. From the perspective of humanistic environment construction, the implementation of cooperative teaching makes teachers have the opportunity to participate in the teaching team and creates collaborative humanity atmosphere. The behavioral expression and teaching attitudes of teachers in cooperative teaching is the best examples for students. Students accept edification of cooperative atmosphere in humanistic environment of cooperative teaching. They can certainly experience caring reliable interpersonal relationship with common purpose. It lays good foundation for the cultivation of ability such as "expression, communication, sharing, respect, and care and team-work spirit".

\section{Talent Cultivation in Schools is Disjointed from Requirements of Society}

At present, the quality and quantity of design teachers in our country lack seriously. Non-professional teachers teach specialized courses. The phenomena that set courses and give lessons according to teachers are common occurrence. It appears abnormal and single education phenomenon; design specialty subdivides excessively and courses appear highly specialized. Graduation design lacks collaboration with related specialties. It leads to the fact that many students in department of design only have single professional design ability. Great gaps exist between talents training standards in schools and social demand of choosing and employing persons. Graduation design is the conclusive teaching link in the last stage for talent cultivation in specialty of art and design, the last and the most important course for students to finish school in the period, the key teaching link to realize training objective of art and design talents, the comprehensive review of knowledge and skill learned in the past, the important teaching link to train students to comprehensively apply knowledge and skill learned by them to analyze and solve practical problems, the centralized reflection of students' professional skills and comprehensive quality, a comprehensive assessment for school-running thought, course system and teaching quality of schools and the 
level of teaching staff, as well as a all-around design practice before students take up working posts. [1] However, at present, many colleges carry out graduation design as well as substituted post exercitation in the last semester, which leads to the fact that the graduation design becomes a mere formality and neglect teaching with serious phenomenon of "free growth"; secondly, because the guidance of teachers is single and young teachers lack experience and ability, it is difficult to guide works with high level and cultivate high-level students.

\section{CONCEPT AND CONNOTATION OF COOPERATIVE TEACHING AND COOPERATIVE EDUCATION}

\section{A. Cooperative Teaching Belongs to Team Teaching, Collaborative Teaching as well as Co-Teaching}

The application of cooperative teaching in design education is long-standing. Early in the period of Bauhaus Weimar, the teaching of the first three and a half years, it carries out teaching arrangement of double-track system that pays equal attention to formal theory and workshop work and common teaching of modeling teachers and technology teachers. Modeling teachers teach painting, color and forms of art. Technology teachers teach handicraft technology and materials, divide teaching contents into sketch and painting, technology, science and theory, make students can accept strong points of pure art and pure technical education and make them become one, in order to develop a preliminary basis for combination of art and industry. At present, schools in American and European countries generally implement Team Teaching (TT for short). The so-called cooperative teaching refers to teachers or personnel concerned who devote themselves to education use the way of collaboration to carry out teaching activities. [1] Cooperative teaching means two or more than two teachers jointly form a teaching team, team members combine personal expertise and potential, aim at one or more subject areas, centralize intelligence and power of people, jointly formulate teaching plans and teaching contents, define division of teaching, give lessons and cultivate students collaboratively. The importance of cooperative teaching lies in solving problems faced by teachers and students in teaching and learning, providing diversified approaches to learning and thinking space for students, broadening students' horizon of learning and giving students more help. Create interactive and cooperative environment, create more opportunities for exchange of teachers and students, then stimulate students' learning interest and improve students' willingness of learning. Through enlightenment of diversified wisdom, cultivate students' team spirit of expression, communication and cooperation and use logical thinking to train students' ability in solving practical problems.

\section{B. Comprehensively Use Teaching Resources and Teachers to Carry out Cooperative Teaching and Cultivate Talents Collaboratively}

At present, the waste of idle resources in colleges, the restriction of exertion space for professional talents are in contradiction with lack of resources such as teachers and equipment. With the help of graduation design, the important teaching link, it will systematically make overall planning for resource disposition and application between school and specialty, school and society, school and enterprise, teacher and teacher, teacher and student, carry out cooperative teaching and cooperative education. The leading role of cooperative teaching is teachers and students. The implementer is teachers. The purpose is to improve students' school record through cooperative teaching and cultivate talents collaboratively.

\section{CONSTRUCTION OF COOPERATIVE TEACHING AND COOPERATIVE EDUCATION MODE}

\section{A. Formation of Cooperative Teaching Team}

According to objective of talents training and requirements of teaching, course directors form team through way of finding cooperative partner voluntarily. Team members are formed by full-time and part-time teachers inside and outside schools, industry experts, designers and engineers. The best combination is the old, middle-aged, and young. The formation takes collaboration of professional field and theme collaboration as the purpose. The responsibility is clear. It includes main teaching and auxiliary teaching. Division of labor of team members in cooperative teaching: course director is responsible to form a team, coordinate with and stimulate team members, edit design and planning courses, give lectures of teaching contents and tutor students; control teaching progress and grasp quality of course teaching; preside over teaching research, communication and sharing; spread knowledge through passing on experience and cultivate teachers. Cooperate with teaching fellow; give full play to their expertise through adopting each other's good points and avoiding their shortcomings, use ways such as case explanation, topic discussion, special lecture and grouping coaching in classroom teaching, cooperate with and coach students, play the role of making up for deficiencies, supplementing knowledge and expanding professional horizon.

\section{B. Content Design of Cooperative Teaching}

Tightly center on the requirements of "five connection" in Opinion on Giving Full Play to Development and Guiding Function of Vocational Education Industry of Ministry of Education, namely "connection between specialty and industry, connection between course content and professional standard, connection between teaching process and productive process, connection between academic certificate and job qualification certificate, and connection between vocational education and lifelong learning". Further carry out specialty investigation, do in-depth analysis on requirements of talents in industry, actively adapt to social and economic development, closely connect with regional economical industry, adjust teaching contents and direction of topic selection accordingly. Strengthen deep collaboration of school and enterprise, perfect university-enterprise cooperation mechanism, in order to cultivate helpful man for economic and industrial development. Give play to collective intelligence of teaching team, construct new system of teaching of graduation design, and realize standard docking between cultivation of art and design talents and professional designers. 
Take display design major of art and design as an example. The major is aimed at cultivating design talents who are good at display design. Its graduation design is divided into two directions such as commercial display design and cultural display design, and four themes. Commercial display design divides into: booth design and store design. On selecting topics, it emphasizes geniality, closely combines with local exhibition economy industry and insists on industry-academy cooperation. On design requirements, it emphasizes connection between art and design and commerce. It not only embodies students' artistic culture and design taste, emphasizes practical function of commercial display design, solve practical problems in design and serve local economy industry. Cultural display design divides into: cultural exhibition hall, science and technology exhibition hall. On selecting topics, it pays special attention to regional culture, history and advanced technology, thinks about the design of local museum, art museum, science and technology museum and planning library, provides carrier and dependence for topic selection of design, contributes ideas and exerts efforts for the development of local culture. On design requirements, it emphasizes profound monographic study, interdisciplinary cooperation and finishes collaboratively through the way of group and team. On teaching, four teachers give lessons in turn within one week and adopt the way of concise and incisive explanation. Each person teaches a theme and lets students have a clear understanding on direction of topic selection of each theme and overall review of knowledge point.

\section{Divide Students into Groups to Do Graduation Design Through team Collaboration}

According to professional talent training plan, personal interests and hobbies and future development vision, divide students into groups and select topic within limited time. Through grouping, hope students can give play to expertise, learn from each other and supplement for each other, with the help of opportunity of learning team collaboration of design, widely dabble at relevant knowledge. Before thesis proposal, according to students' topic selection, each specialty organizes teachers and students to carry out discussion and field research, let teachers and students give an insight into project background to ensure that the topic selection of graduation design is true and reasonable. ${ }^{[2]}$ Through graduation design, let students comprehensively apply relevant theoretical knowledge and design skills of this specialty, make in-depth research on a topic or direction, train students' analytical ability, stimulate students' creativity, then improve and consolidate students' manipulative ability and expressive ability as well as toughen students' professional quality. Make graduation design through ways of professional cooperation, grouping cooperation, theme cooperation and team cooperation, make each person's role, responsibility and obligation clear and definite, and share guidance from teaching team.

\section{Design through Circulating Teaching Method}

Teachers base on their expertise, adopt the way of concise and incisive explanation to carry out circulating teaching; take case study and case counsels as the entry points to guide students to make graduation design; give cooperative training for students through group discussion, role play and workplace simulation. Teachers base on students' grouping and topic selection, adopt ways of centralized teaching, group teaching or studio form to teach, combine case guidance with collaborative guidance. Teachers base on teaching progress and teaching requirements and adopt flexible and diversified teaching methods to stimulate students to learn, such as special topic teaching, example explanation and case guidance, guide students to implement preparation for subject study, assignment discussion and assignment report. Then inspire students' design thinking, absorb professional knowledge through multiple ways, broaden professional horizon, realize cross-border integration of resources and cultivate students' spirit of teamwork. In circulating teaching, the field of teaching is not limited to school. It can be places such as professional market, design companies, production companies and project site outside school. Students can share guidance of teachers from different specialties and fields and solve many problems in graduation design. Let students get knowledge edification and training of skills imperceptibly, then achieve teaching objectives of graduation design.

\section{E. Quality Evaluation Design of Cooperative Teaching}

Evaluation of teaching quality is a systematic project, in order to check whether it reaches teaching objectives. The evaluation of teaching quality is not the end point but start point. The significance of evaluation lies in improving teaching. Its quality evaluation mainly includes: 1 . Evaluation of professional skills and subject ability. According to completion status and completion process of graduation design, check the ability in analyzing and solving problems, including master degree of topic selection, design concept, design expression, design innovation, and comprehensive application of learned knowledge and skills. 2. Evaluation of teamwork and collaborative design ability. Observe and record students' performance in design process of project, check task allocation, mutual cooperation and implementation of project of members, evaluate students' degree of contribution for the project, pay attention to students' individual performance, teamwork and collaborative design situation. 3. Evaluation of communication and expression ability. Through observing students' response for teachers' questioning, their expression and intonation in answering questions and discussion between students in teaching field, understand students' understanding and master degree of knowledge. Through questioning in regular meeting, project discussion and project defenses, pay attention to students' expression ability and communication ability. Communication ability includes oral expression and written expression. Oral expression pays attention to students' daily performance and evaluation in thesis proposal, medium term and graduation thesis defense process. The evaluation of written expression ability is carried out through personal summary and design report. 4. Evaluation through questionnaire, investigation and survey as well as interview. The main contents of interview and questionnaire design include:

- evaluate advantages and disadvantages of courses of cooperative teaching; 
- evaluate whether the design of teaching activities is systematic, scientific, rigorous and meaningful;

- evaluate whether it reaches anticipative aim of course teaching;

- compared with traditional teaching model, evaluate whether cooperative teaching is more conducive to learning and improves professional skills and teaching quality;

- the comprehensive evaluation of teaching results is mainly embodied in: Comparison of employment rate, level of salary, graduation design results with graduates in non cooperative teaching class; comparison of degree of satisfaction between teachers and students; help for teaching reform and professional building; comparison of help for future work of teachers and students;

- generally speaking, evaluate whether the cooperative teaching is superior to non cooperative teaching, find opinions and suggestions for improvement.

\section{F. Operation Design of Cooperative Teaching}

- Regularly hold teaching seminars. Members in teaching team take counsel together about how to divide the work to carry out cooperative teaching. Team leaders are responsible for supervising teaching in the entire process, comprehensively consider a variety of variables, and regularly hold teaching seminars and coordination committee, timely solve problems appeared in teaching.

- Record process and write design report. Require students to write learning journal and design report every week, strengthen students' ability in recording problems and writing design report. According to students' record and report, teachers timely grasp course progress and situation and make timely adjustment and division of labor.

- Regularly interact, communicate and discuss. Carry out group discussion and seminar every weak. The discussion can be implemented between students and students as well as students and teachers. Through discussion, timely find difficulties and bottlenecks faced by students in the process of graduation design, know students' attitudes towards problem handling and cultivate students' innovative thinking and team awareness.

- Defense and exhibition of works. Through graduation design defense, express design idea and show charm and results of individuality and team. Display students' graduation design results, and accept review of the society. Compile excellent graduation design results into electronic materials, put them on the website or library for follow-up students of graduation design to learn and refer to.

\section{EFFECT OF COOPERATIVE TEACHING AND COOPERATIVE EDUCATION}

\section{A. Create Cooperation Atmosphere, Co-create Cooperative Cultural Person and Promote the Construction of Teaching Team}

Cooperative teaching helps to create good teaching atmosphere and cooperation environment and lets teachers have more opportunities to participate in teaching. Guide teachers to formulate teaching standards, teaching objectives and teaching contents together to carry out teaching and talents cultivation collaboratively. Enhance emotions between teachers and teachers, teachers and students, train skills to communicate with people, and effectively make up for lack or deficiency of teachers in specialty, get rid of individualism, cocreate collaborative culture and construct teaching team.

\section{B. Adopt Good Points and Avoid Shortcomings, Divide the Work Reasonably, Supplement for Each Other to Reach the Situation that Teaching Benefits Teachers as well as Students}

In the process of participating in cooperative teaching, teachers can adopt good points and avoid shortcomings, choose unit that they are familiar with to teach, give full play to their professional ability. Teachers can learn skills about how to assign tasks, discuss and dispel conflicts. Through cooperative teaching, they have the opportunity to know about cognition and teaching methods of other teachers for the same course, enhance communication and discussion between teachers, promote experience sharing and emotional cultivation between teachers. Let teachers have space to exert. Under the effect of "pass, help and drive", they can share ideas, comment on each other, inspect and learn from each other's work, improve teaching ability, get professional development, ${ }^{[3]}$ promote teaching reflection and drive teaching reform.

\section{Diversified Learning Broadens Professional Horizon, Exchange Interaction Strengthens Learning Interest and Improves Learning Effectiveness}

Cooperative teaching uses the way of team to give lessons to meet requirements of different students. Its diversified, systematic and circulatory teaching model can stimulate students' learning interests and bring students sense of curiosity and expectation. From the perspectives of cognitive psychology and neuropsychology, sense of curiosity can improve students' learning effectiveness, namely novelty effect and effectively influence students' memory of what they have learned. ${ }^{[1]}$ Through cooperative teaching, students can know teachers of other relevant majors, accept different ideas, avoid the limitation of single teaching of teachers, and let students get more help and guidance; can broaden students' professional horizon, learn more professional and comprehensive knowledge; train students' adaptability, critical thinking skills and ability of solving problems, arouse their potential to solve problems of graduation design; through rich and colorful and creative teaching activities, arouse students' motivation to discuss theme of learning and contents, increase issues for teachers and students to exchange and discuss, guide students to actively ask questions, promote communication 
between teachers and students, effectively improve students' professional quality and ability, professional quality and strain capacity and cultivate students' team spirit.

\section{PROFOUND CONSIDERATION ON COOPERATIVE TEACHING AND COOPERATIVE EDUCATION}

\section{A. Need Powerful Team Spirit}

Team of cooperative teaching needs to have powerful cohesive force, executive force and certain flexibility. Or cooperative teaching will be in a state of disunity and will not help teaching to reach teaching objectives and go against students' learning. Interaction between teams and division of roles and responsibilities, teachers' experience, moral quality, style, attitude, ability to communicate, degree of enthusiasm of cooperative teaching activities are key factors to influence the success or failure of cooperative teaching. Meanwhile, it needs to spend more time in communicating and coordinating conflicts and challenges between teachers timely.

\section{B. Need Scientific Overall Planning}

Compared with traditional teaching, cooperative teaching needs more preparations. Besides, the procedure is heavy and complicated. It is difficult to coordinate teaching contents and time of teachers, plan teaching places and teaching resources as a whole. Meanwhile, teaching seminars and coordination meetings will also increase. Teachers need some time to adapt. Before classes begin, carry out pre-class analysis according to requirements of graduation design of different specialties, course connection, teaching object and characteristics of students. In order to avoid that teaching contents are repeated and unnecessary, ensure that the teaching contents are scientific and logic, formulate scientific and rigorous teaching contents of graduation design, protocol cooperative teaching methods and models and let teaching of graduation design, teachers and students get the biggest efficiency.

\section{Need More Flexible Time and Space}

The diversity and flexibility of cooperative teaching model need more flexible teaching time and space, plan and apply more teaching resources, continuous amendment and perfection as well as understanding and support of teaching administrative department. Let students obtain more learning contents and opportunities to discuss with each other. Once they find deficiencies, timely cut in and supplement deficiencies of knowledge, flexibly increase teaching contents and knowledge points.

\section{Need the Participation of Interdisciplinary Students}

Looking from cultivating students' cross-border integration design capacity, it needs not only interdisciplinary teachers, but also collaboration of interdisciplinary students. They shall create more opportunities for specialties and classes to inspect and learn from each other's work. Guide students of different specialties to give play to their specialty advantages to do the same task collaboratively, take charge the design of certain fields, carry out graduation design with teamwork and cultivate students' spirit of cross-border integration and teamwork.

\section{E. Need Pragmatic Spirit and the Courage to Raise Questions}

Although teachers in the team get emotional support, it also lets them unwilling to destroy the harmonious relationship. Therefore, they escape serious reflection. In order to avoid hurting the feeling, it is impossible for teachers to deeply discuss problems. They are unwilling to directly face and dispose conflicts. Therefore, they adopt compromise strategy to reduce the possibility of critical analysis, which will not help teaching reform of courses.

\section{CONCLUSION}

For specialty of art and design in higher vocational education, the teaching of graduation design has specific connotation. Graduation design adopts teaching models of cooperative teaching and cooperative education. It is the key to cultivate students with thinking ability of systematic design, overall design concept, and design capacity of cross-border integration and cooperative spirit of group. It is also innovative practice of talents training mode in higher vocational art and design education. It isn't simple superposition between teachers and students, but to cultivate talents through mutual learning, mutual coordination and mutual cooperation between them. It is the key to success or failure of cooperative teaching and cooperative education to scientifically conclude rules of cooperative teaching and cooperative education, systematically plan and design curriculum, with powerful team cohesiveness, executive force and certain flexibility; the implementation of cooperative teaching and cooperative education pattern can help teachers to adopt good points and avoid shortcomings, give play to professional strong point and learn from each other to achieve the effect that teaching benefits teachers as well as students; provide students with instructors in different professional fields, urge students' professional development and promotion of knowledge, guide students to take the initiative to ask questions, put forward questions and discuss questions to form good atmosphere of active learning, train students' ability in cross-border integration design, solve problems in many fields of graduation design; it can strengthen communication and connection between teachers and students as well as students and students, create team culture, cultivate cooperative spirit of group; increase research and discussion on course teaching and promote teaching reform. Since our school carries out teaching reform of graduation design of cooperative teaching and cooperative education, students' employment rate and quality have improved further. Students' works have the honor to win numerous national design awards. Students get the affirmation of society and favorable reception from employers. The teaching reform achievement has won the second prize of national teaching achievements. Cultivation of art and design talents in institution of higher learning in our country shall learn from it.

\section{REFERENCES}

[1] Peng Huarong. Current Situation and Reflection of Talent Cultivation in Specialty of Art and Design in Higher Vocational Education [J], Grand Stage, the 4th issue in 2013 
[2] Zeng Ruilian. Lin Zhicheng. New Pattern of Cooperation between Museum and School: Thematic Curriculum of Cooperative Planning of Museum and School Teachers and Implementation Course-Take World Geography Reconnaissance Battalion as an Example [J], Technology Museum Review, 2014/12.55-85, Taiwan

[3] Chen Yulan. Discussion on Countermeasures for Implementation of Cooperative Teaching and Teacher Education [J], Science of Education 2003/06.57-78, Taiwan

[4] Wu Bixia. Case Study in Learning Field of Integrative Activities by Using Cooperative Teaching Model [D], master thesis of Institute of Curriculum and Instruction in National Taipei Normal College, 2004, Taipei City

[5] Liu Xinsheng. Practice Research on Cooperative Teaching of Thematic Learning of Comprehensive Practical Activity [D], master thesis of Northeast Normal University, 2011-06-01

[6] Lin Ruilin. Influence of Teachers' Cooperative Teaching on Learning Achievement of Students in School of Design [J], Journal of Taipei Municipal University of Education, the 2nd issue of 39th volume in the republic of China in 97

[7] Luo Xiling, Ha Congying, Zhang Youguang. Exploration and Practice on Graduation Design of Team Cooperation Mode [J], Research and Exploration in Laboratory, March 2014 